\title{
Влияние пролактина на иммүнные характеристики у женщин с аутоиммунным тиреоидитом
}

\section{О.А. Гончарова}

Харьковская медицинская академия последипломного образования

\begin{abstract}
Резюме. Результаты могут быть использованы для совершенствования патогенетической терапии аутоиммунного тиреоидита. Цель - установление особенностей иммунного статуса у женщин с аутоиммунным тиреоидитом (АИТ) в зависимости от уровней пролактина (ПРЛ). Материал и методы. Обследованы 90 женщин с АИТ и субкомпенсированным гипотиреозом: исследованы базальные уровни ПРЛ, тиреотропного гормона (ТТГ), свободного тироксина (свТ ${ }_{4}$. В подгруппах с гипер- и нормопролактинемией (ГПРЛ, НПРЛ) изучены иммунофенотип лимфоцитов (CD3, CD4, CD8, CD16, CD22), уровень антитиреоидных антител к тиреоглобулину (АТТГ) и тиреопероксидазе (АтТПО). Результаты. ГПРЛ имела место в 35,5\% случаев, ее наличие сопровождалось более выраженным гипотиреозом ( $<<0,05$ для повышения уровня ТТГ и p<0,05 для снижения концентрации св $T_{4}$ ) по сравнению с группой с НПРЛ. Все исследованные показатели клеточного иммунитета, а также АтТПО в группе с ГПРЛ были достоверно выше, чем у пациенток с НПРЛ. Установлены достоверные ассоциативные связи между показателями ПРЛ и клеточного иммунитета, а также АтТПО. Выводы. Наличие гиперпролактинемии у пациенток с АИТ провоцирует снижение эффективности заместительной терапии гипотиреоза. Гиперпролактинемия может расцениваться как стимулятор иммунопатогенетического звена аутоиммунного тиреоидита. Повышенные уровни пролактина ассоциируются с повышением уровней T-, В-лимфоцитов, натуральных киллеров и провоцируют усиление выработки антитиреоидных антител.
\end{abstract}

Ключевые слова: пролактин, аутоиммунный тиреоидит, иммунофенотип лимфоцитов.

Тесная связь между пролактином (ПРЛ) и аутоиммунной тиреопатологией подтверждается целым рядом исследований. Установлено, что при первичном гипотирео-

\footnotetext{
* Адреса для листування (Correspondence): Харьковская медицинская академия последипломного образования, вул. Амосова, 58, м. Харків, 61176, Україна. E-mail: oagoncharova18@gmail.com

๑ О.А. Гончарова
}

зе гиперпролактинемия (ГПРЛ) выявляется почти у 40\% больных аутоиммунным тиреоидитом (АИТ). Есть данные, что частота АИТ среди пациентов с пролактиномой составляет $21,0 \%$ (23,2\% среди женщин и $12,6 \%$ среди мужчин) [1, 2]. В 51,5\% случаев пролактиному диагностировали до развития АИТ, в $37,2 \%$ 
наблюдений обе патологии выявляли одновременно, и в 11,3\% вначале диагностировали АИТ [3, 4].

ПРЛ представляет собой полипептидный гормон, который синтезируется лактотрофами передней доли гипофиза. Ген, кодирующий синтез ПРЛ, имеет два независимых промотора: проксимальный, регулирующий транскрипцию в гипофизе, и супердистальный, отвечающий за транскрипцию в негипофизарных клетках [5]. Внегипофизарный промотор регулирует транскрипцию ПРЛ в лимфоцитах. Его полиморфизм ассоциирован с повышением риска аутоиммунных заболеваний [6]. Кроме того, внегипофизарный промотор находится в маммарных, эпителиальных и жировых клетках [7].

Относительно влияния ПРЛ на иммунную систему установлено, что при уровне ПРЛ 100 нг/мл в эксперименте у мышей активируется выработка провоспалительных цитокинов (ФНО- $\alpha$, ИЛ-1 $\beta, \gamma$-ИНФ, ИЛ-12), однако очень высокая концентрация ПРЛ (1000 нг/ мл) усиливает секрецию противовоспалительного цитокина ИЛ-10 [8, 9]. Воздействие высокими дозами ПРЛ на дендритные клетки (ДК) стимулирует их созревание до функционально активных антиген-презентирующих клеток, способных активировать пролиферацию Т-клеток и продукцию $\gamma$-ИНФ [10]. Также ПРЛ стимулирует спонтанную цитотоксичность натуральных киллеров (NK) [11, 12]. Все эти результаты в совокупности позволяют предполагать, что ПРЛ может играть существенную роль в развитии аутоиммунных заболеваний. В пользу этого свидетельствуют и данные эпидемиологических исследований относительно прогрессирования аутоиммунных процессов во время беременности и в послеродовой период с их ГПРЛ [13].

Взаимосвязь между тиреоидной и гонадной системами осуществляется и на уровне гипоталамо-гипофизарного аппарата, и на уровне действия периферических гормонов. При первичном гипотиреозе повышается секреция тиролиберина (являющегося одновременно пролактолиберином) в гипоталамусе и тиреотропного гормона (ТТГ) гипофиза, и в связи с этим возрастает секреция ПРЛ [14]. Поскольку ПРЛ является паракринным и системным стимулятором аутоиммунитета [15], регулирование его уровня при аутоиммунных тиреоидных заболеваниях можно считать одним из звеньев патогенетической терапии этой патологии.

Цель данного исследования состояла в установлении особенностей иммунного статуса у женщин с аутоиммунным тиреоидитом в зависимости от уровней пролактина.

\section{Материал и методы}

Обследованы 90 женщин в возрасте от 19 до 44 лет $(31,23 \pm 4,15$ года) с АИТ и гипотиреозом в состоянии медикаментозной субкомпенсации, которые не менее года получали индивидуально подобранную заместительную тиреоидную терапию.

Исследование базального уровня ПРЛ, свободного тироксина (св $\left.\mathrm{T}_{4}\right)$ и ТТГ проводили иммуноферментным методом с помощью стандартных наборов фирмы «Алкор Био» (РФ) на иммуноферментном анализатope StatFax 3100, 2008 (Immunotech, США). Концентрацию гормонов рассчитывали с помощью калибровочной кривой и выражали в мЕД/мл для ПРЛ и ТТГ, пмоль/л для св . $_{4}$ Также иммуноферментным методом исследованы антитела к тиреоглобулину (АтТГ) и тиреопероксидазе (АтТПО).

Изучали иммунофенотип лимфоцитов с использованием стабильных диагностикумов на основе моноклональных антител к CD3+ (зрелые Т-лимфоциты), CD4+ (Т-лимфоциты хелперы/индукторы), $\mathrm{CD} 8+$ (Т-лимфоциты киллеры-супрессоры), CD20+ (антителопродуцирующие В-лимфоциты) и CD16+ (натуральные киллеры - NK-клетки). Данные представлены в относительных показателях (\%).

Статистический анализ результатов проведен методами вариационной статистики с помощью стандартного пакета статистических расчетов. Данные проверялись на нормальность распределения с помощью метода КолмогороваСмирнова. В связи с установленной нормальностью распределения применялись методы параметрической статистики. Данные представлены в виде среднего арифметического и статистической ошибки среднего арифметического $(\mathrm{M} \pm \mathrm{m})$. Сравнение средних количественных величин проводили с использованием t-критерия Стьюдента. Статистически значимыми считали 
различия при $\mathrm{p}<0,05$. Для изучения связи между показателями использовали метод корреляционного анализа с определением коэффициента корреляции (r) и установлением его значимости по t-критерию с 95\% уровнем надежности $(\mathrm{p}<0,05)$.

\section{Результаты и обсуждение}

По результатам изучения гормонального статуса у больных (табл. 1) ГПРЛ среди женщин с АИТ виявили в $35,5 \%$ случаев, что согласуется с данными других авторов - 40-47\% [3, 4, 16]. Наличие ГПРЛ у женщин с АИТ сопровождалось более выраженным гипотиреозом $(\mathrm{p}<0,05$ для уровня ТТГ и $\mathrm{p}<0,05$ для уровня $\mathrm{cв}_{4}$ ) по сравнению с группой с нормопролактинемией (НПРЛ), несмотря на индивидуально подобранную заместительную тиреоидную терапию, получаемую пациентками не менее года. Можно предположить, что при АИТ на фоне ГПРЛ снижается эффективность заместительной тиреоидной терапии.

Состояние клеточного и гуморального иммунитета у женщин с АИТ в условиях НПРЛ и ГПРЛ представлено в табл. 2. Выявленные нами достоверные различия в показателях клеточного иммунитета и уровнях АтТПО в зависимости от уровня ПРЛ подтверждают существенную его роль в иммуногенезе АИТ, причем в качестве иммуностимулятора, что согласуется с данными других исследователей [17]. В научных публикациях последнего 10-летия связь между ПРЛ и аутоиммунной патологией объясняют способностью ПРЛ синергично с ИЛ-2 запускать пролиферацию Ти В-лимфоцитов и NК-клеток, стимулировать созревание дендритных клеток и синтез антител. Эти процессы обеспечиваются экспрессией клетками иммунной системы на своей поверхности рецепторов к ПРЛ, которые активируются при связывании с соответствующими лигандами, а также способностью самих иммунных клеток продуцировать ПРЛ [18].

Анализ ассоциативных связей между ПРЛ и показателями иммунного статуса у женщин с АИТ (табл. 3.) свидетельствует, что в условиях ГПРЛ и НПРЛ имеется достоверная прямая ассоциативная связь уровней ПРЛ c характеристиками клеточного иммунитета (за исключением Т-супрессоров - CD8 на таблица 1. Показатели тиреоидного статуса у женщин с аутоиммунным тиреоидитом в зависимости от уровня пролактина $(\mathrm{M} \pm \mathrm{m})$

\begin{tabular}{|c|c|c|c|}
\hline $\begin{array}{l}\text { Показатель } \\
\text { (норма) }\end{array}$ & $\begin{array}{l}\text { Гиперпролакти- } \\
\text { немия }(\mathrm{n}=32)\end{array}$ & $\begin{array}{l}\text { Нормопролакти- } \\
\text { немия }(n=58)\end{array}$ & $p$ \\
\hline $\begin{array}{l}\text { ПРЛ, мМЕ/л } \\
\text { (100-530) }\end{array}$ & $705,08 \pm 15,41$ & $321,16 \pm 10,29$ & $<0,001$ \\
\hline $\begin{array}{l}\text { ТТГ, мЕД/мЛ } \\
(0,4-4,3)\end{array}$ & $5,98 \pm 0,81$ & $3,64 \pm 0,76$ & $<0,05$ \\
\hline $\begin{array}{l}\mathrm{cBT}_{4}, \text { пмоль/л } \\
(10-23)\end{array}$ & $9,08 \pm 1,62$ & $12,9 \pm 0,76$ & $<0,05$ \\
\hline
\end{tabular}

Таблица 2. Состояние клеточного и гуморального антитиреоидного иммунитета у женщин с АИТ в зависимости от уровня пролактина (M $\pm \mathrm{m})$

\begin{tabular}{llll}
\hline $\begin{array}{l}\text { Показатель, \% } \\
\text { (норма) }\end{array}$ & $\begin{array}{l}\text { Гиперпро- } \\
\text { лактинемия } \\
\text { (n=32) }\end{array}$ & $\begin{array}{l}\text { Нормопро- } \\
\text { лактинемия } \\
(\mathbf{n = 5 8 )}\end{array}$ & $\mathbf{P}$ \\
\hline CD3, 50-80 & $59,74 \pm 1,82$ & $52,43 \pm 1,64$ & $<0,05$ \\
CD4, 33-46 & $47,38 \pm 2,88$ & $36,61 \pm 1,80$ & $<0,01$ \\
CD8 17-30 & $29,30 \pm 1,54$ & $19,12 \pm 1,32$ & $<0,001$ \\
CD16, 12-23 & $19,44 \pm 1,02$ & $15,61 \pm 1,03$ & $<0,05$ \\
CD22, 17-31 & $27,59 \pm 1,31$ & $19,91 \pm 1,27$ & $<0,05$ \\
АТТГ, <65 & $276,24 \pm 51,59$ & $221,27 \pm 68,49$ & - \\
АТТПО, <30 & $463,36 \pm 69,33$ & $395,88 \pm 62,17$ & $<0,001$ \\
\hline
\end{tabular}

Таблица 3. Ранговые коэффициенты по Спирмену между уровнем ПРЛ и показателями иммунного статуса у женщин с аутоиммунным тиреоидитом

\begin{tabular}{|c|c|c|c|c|}
\hline \multirow[t]{2}{*}{ Показатель } & \multicolumn{2}{|c|}{$\begin{array}{l}\text { Гиперпролактинемия } \\
(\mathrm{n}=32)\end{array}$} & \multicolumn{2}{|c|}{$\begin{array}{l}\text { Нормопролактинемия } \\
(\mathrm{n}=58)\end{array}$} \\
\hline & $r$ & $p$ & $r$ & $\mathbf{p}$ \\
\hline CD3+ & 0,391 & $<0,05$ & 0,565 & $<0,01$ \\
\hline CD4+ & 0,427 & $<0,05$ & 0,566 & $<0,01$ \\
\hline CD8+ & 0,371 & $<0,05$ & 0,144 & - \\
\hline CD16+ & 0,392 & $<0,05$ & 0,602 & $<0,001$ \\
\hline CD22+ & 0,601 & $<0,001$ & 0,349 & $<0,05$ \\
\hline АтТГ & 0,061 & - & 0,146 & - \\
\hline АтТПО & 0,407 & $<0,05$ & 0,244 & - \\
\hline
\end{tabular}

фоне НПРЛ). Что касается ассоциации с показателями гуморального иммунитета, то она определена только относительно АтТПО и только в условиях ГПРЛ.

В целом результаты исследования свидетельствуют о выраженном иммуностимулирующем действии ПРЛ при АИТ с гипотиреозом, и этот факт необходимо учитывать для совершенствования иммуномодулирующей терапии данного заболевания. 


\section{Выводы}

1. Наличие гиперпролактинемии у пациенток с АИТ провоцирует снижение эффективности заместительной тиреоидной терапии.

2. Гиперпролактинемия может расцениваться как стимулятор иммунопатогенетического звена при аутоиммунном тиреоидите.

3. Увеличение уровня пролактина в крови ассоциируется с повышением уровней Т-, В-лимфоцитов, натуральных киллеров и стимулирует синтез антитиреоидных антител.

\section{Список использованной литературы}

1. Elenkova A, Petrossians P, Zacharieva S, Beckers A. High prevalence of autoimmune thyroid diseases in patients with prolactinomas: a cross-sectional retrospective study in a single tertiary referral centre. In Annales d'endocrinologie. 2016;77(1):37-42.

2. Строев ЮИ, Чурилов ЛП. Случай бесплодного брака, связанной с аутоиммунным тиреоидитом и клинически бессимптомной макроаденомой гипофиза (пролактиномой). Клиническая патофизиология. 2016;22(1):72-79. (Stroev YuI., Churilov LP. A case of infertile marrige related to autoimmune thyroiditis and clinically latent pituitary macroadenoma (prolactinoma). Clinical pathophysiology. 2016;1:72-79).

3. Иванова ГП, Горобец ЛН. Психоэндокринные аспекты проблемы хронического аутоиммунного тиреоидита у женщин репродуктивного возраста. Журнал неврологии и психиатрии им. С.С. Корсакова. 2010;110(1):33-41. (Ivanova GP, Gorobets LN Psychoendocrinological aspects of chronic autoimmune thyroiditis in women of reproductive age. S.S. Korsakov Journal of Neurology and Psychiatry. 2010;110(1):33-41).

4. Сохадзе ХС, Сабуров АВ, Гаврилова НП. Реализация программы вспомогательных репродуктивных технологий у женщин с гиперпролактинемией и дисфункцией щитовидной железы. Фундаментальные исследования. 2013;9-4:734743. (Sokhadze KS, Saburov AV, Gavrilova NP. Implementation of the assisted reproductive technology program in women with hyperprolactinemia and thyroid dysfunctions. Fundamental research. 2013;9(part 4):734-743).

5. Ben-Jonathan N, LaPensee CR, LaPensee EW. What can we learn from rodents about prolactin in humans? Endocr. Rev. 2008;29:1-41.

6. Stevens A, Ray D, Alansari A, Hajeer A, Thomson W, Rachelle Donn R, Ollier WER, Worthington J, Davis JRE. Characterization of a prolactin gene polymorphism and its associations with systemic lupus erythematosus. Arthritis Rheum. 2001;44(10):2358-2366.

7. Али Н, Каледина ЕА, Петяева АВ, Строев ЮИ, Чурилов ЛП Гиперпролактинемия и аутоиммунитет. Клиническая патофизиология. 2018;3:27-38. (Ali N, Kaledina E, Petyaeva A Stroev $\mathrm{Yu}$, Churilov L. Hyperprolactinemia and autoimmunity. Clinical pathophysiology. 2018;4:30-37).

8. Tripathi A, Sodhi A. Production of nitric oxide by murine peritoneal macrophages in vitro on treatment with prolactin and growth hormone: involvement of protein tyrosine kinases, $\mathrm{Ca}(++)$, and MAP kinase signal transduction pathways. Mol. Immunol. 2007;44:3185-3194.

9. Tripathi A, Sodhi A. Prolactin-induced production of cytokines in macrophages in vitro involves JAK/STAT and JNKMAPK pathways. Int. Immunol. 2008;20:327-346.

10. Carreno PC, Jimenez E, Sacedon R, Vicente A, Zapata AG Prolactin stimulates maturation and function of rat thymic dendritic cells. J. Neuroimmunol. 2004;153:83-90.
11. Sun R, Li AL, Wei HM, Tian ZG. Expression of prolactin receptor and response to prolactin stimulation of human NK cell lines. Cell. Res. 2004;14:67-73.

12. Попова ЕВ, Тиньков АА, Никаноров АА, Попова ЮВ, Караулов АВ. Влияние пролактина на иммунитет при стрессе. Иммунопатология, аллергология, инфектология. 2016;1:14-19. (Popova EV, Tinkov AA, Nikonorov AA, Popova YV, Karaulov AV. Influence of prolactin into immunity in stress. International journal of immunopathology, allergology, infectology. 2016;1:14-19).

13. Orbacha H, Shoenfeld Y. Hyperprolactinemia and autoimmune diseases. Autoimmun. Rev. 2007;6(I.8):537-542.

14. Строев ЮИ, Чурилов ЛП. Эндокринология подростков - СПб: Эл-Би-СПб, 2004. - С. 119-207. (Stroyev Yu L, Churilov LP. The Endocrinology of the Adolescents.ELBI-SPbSU, 2004:119-207).

15. Шабанова СШ, Алекберова 3С. Нейроэндокринология и аутоиммунитет - современные перспективы. Научн-практ. ревматол. 2010;1:24-31. (Shabanova SSh, Alekberova ZS Neuroendocrinology and autoimmunity: current aspects. Rheumatology Science and Practice. 2010;48(1):24-31).

16. Субхангулов ЗМ, Давлетшин РА, Давлетшина ГК, Сафина АЗ. Пролактин и его взаимоотношение с цитокинами при аутоиммунном тиреоидите. Иммунол и клин иммунол. 2007;28(5):300303. (Subhangulov Z, Davletshin R, Davletshina A. Prolactin and its relationship with cytokines in autoimmune thyroiditis. Immunology. 2007:28(5):300-303).

17. Максимова АВ, Пинигина ЮИ, Строев ЮИ, Чжао Ваньлун, Чурилов ЛП. Аутоиммунный тиреоидит Хасимото, гипотиреоз, пролактин и женская репродуктивная система. Актуальные пробл. транспортной медицины. 2011;2(24):122-130. (Maximova AV, Pinigina YuI, Stroev YuI, Zhao W, Churilov LP. Hashimoto's autoimmune thyroiditis, hypothyroidism, prolactin and the female reproductive system. Actual problems of transport medicine. 2011;2:122-130).

18. Али Нурин Петяева АВ, Каледина ЕА, Строев ЮП, Чурилов ЛП. Гиперпролактинемия и аутоиммунитет. Клин. патофизиология. 2018;24(3):27-39. (Ali N, Kaledina EA, Petyaeva AV, Stroev YI, Churilov LP. Hyperprolactinemia and autoimmunity. Clinical pathophysiology. 2018;3:27-39)

(Надійшла до редакції 06.02.2020р.)

\section{Вплив пролактину на імунні показники в жінок з автоімунним тиреоїдитом}

\section{О.А. Гончарова}

Харківська медична академія післядипломної освіти

Резюме. Результати можуть бути використаними для вдосконалення патогенетичної терапії автоімунного тиреоїдиту. Мета - встановлення особливостей імунного статусу в жінок з автоімунним тиреоїдитом (AIT) залежно від рівнів пролактину (ПРЛ). Матеріал і методи. Обстежено 90 жінок з АІT і субкомпенсованним гіпотиреозом: досліджено базальні рівні ПРЛ, тиреотропного гормону (ТТГ), вільного тироксину $\left(\mathrm{BT}_{4}\right)$. У підгрупах із гіпер- і нормопролактинемією (ГПРЛ, НПРЛ) вивчено імунофенотип лімфоцитів (CD3, CD4, CD8, CD16, CD22), рівні антитіл до тиреоглобуліну (АтТГ) і тиреопероксидази (АтТПО). Результати. ГПРЛ мала місце в 35,5\% випадків, наявність ГПРЛ супроводжувалась більш вираженим гіпотиреозом ( $p<0,05$ для підвищення ТТГ і $p<0,05$ для зниження в $T_{4}$ ) порівняно з групою з НПРЛ. Усі досліджені показники клітинного імунітету, а також АтТПО в групі з ГПРЛ були вірогідно вищими. Встановлено достовірні асоціативні зв'язки між ПРЛ і показниками клітинного 
Оригінальні дослідження

імунітету, а також АтТПО. Висновки. Наявність гіперпролактинемії в пацієнток з АІT негативно впливає на ефективність замісної тиреоїдної терапії гіпотиреозу. Гіперпролактинемія може розцінюватись як стимулятор імунопатогенетичної ланки автоімунного тиреоїдиту. Збільшення вмісту пролактину в кров асоціюється з підвищенням рівнів Т-, В-лімфоцитів, натуральних кілерів, а також стимулює синтез антитиреоїдних антитіл.

Ключові слова: пролактин, автоімунний тиреоїдит, імунофенотип лімфоцитів.

\section{Effect of prolactin on the immune parameters in women with autoimmune thyroiditis}

\section{O.A. Goncharova}

Kharkiv medical academy of postgraduate education

Abstract. The results can be used to improve the pathogenetic therapy of autoimmune thyroiditis. Goal. To set the immune status features in women with autoimmune thyroiditis (AIT) depending on prolactin levels (PRL). Material and methods. 90 women with AIT and subcompensated hypothyroidism were examined: basal levels of PRL, thyroid-stimulating hormone (TSH), and free thyroxine (fT4) were studied. In subgroups with hyper- and normoprolactinemia (GPRL, NPRL), the immunophenotype of lymphocytes (CD3, CD4, CD8, CD16, CD22), the level of antithyroid antibodies to thyroglobulin (ATTG) and thyroperoxidase (ATTPO) were studied. Results. GPRL occurred in $35.5 \%$ of cases, its presence was accompanied by more pronounced hypothyroidism ( $p<0.05$ to increase the level of TSH and $p<0.05$ to decrease fT4) compared with the group with NPRL. All studied parameters of cellular immunity, as well as AbTPO in the group with GPRL were significantly higher than with NPRL. Reliable associative relationships between PRL and indicators of cellular immunity, as well as AbTPO, have been established. Conclusions. The presence of hyperprolactinemia in patients with AIT reduces the effectiveness of thyroid replacement therapy for hypothyroidism. Hyperprolactinemia can be regarded as a stimulant of the immunopathogenetic link in autoimmune thyroiditis. Prolactin is associated with level increassion of T-, B-lymphocytes, natural killer cells and helps to increase the synthesis of antithyroid antibodies.

Keywords: prolactin, autoimmune thyroiditis, immunophenotype of lymphocytes. 